\title{
Combined Up- and Downgaze Palsy Associated Temporarily with a Unilateral Midbrain Infarction
}

\author{
Shinsuke Fujioka Masashi Nakajima \\ Department of Neurology, Tokyo Rosai Occupational Diseases and Injuries Hospital, Tokyo, Japan
}

\begin{abstract}
Dear Sir,
Combined up- and downgaze palsy usually results from bilateral involvement of the upper midbrain tegmentum. In rare instances, however, it results from a unilateral lesion [1-3], of which the mechanisms remain unknown [4]. We report a patient with unilateral midbrain tegmentum infarction who presented temporarily with non-dissociated, combined up- and downgaze palsy.
\end{abstract}

\section{Case Report}

A 75-year-old right-handed man with hypertension, type 2 diabetes, hyperlipidemia, and prior myocardial infarction presented with horizontal diplopia in all fields of gaze immediately after he underwent a follow-up coronary angiography. He had a past history of lacunar infarction in the right thalamus, which caused dysesthesias on his left side that had lasted for a few months. His initial neurological examination $4 \mathrm{~h}$ after the onset of diplopia was significant for impairment of vertical gaze and convergence. His eyes were level on forward gaze, and both upward and downward eye movements were absent even on oculocephalic maneuvers. Horizontal saccades and pursuit were normal. The pupils were unequal, slightly smaller on the left, and reactive normally to light, associated with subtle left eyelid ptosis. Five days later, his diplopia had resolved. On voluntary vertical gaze, trace upward and downward movement returned. Oculocephalic maneuver elicited downward saccade but failed to hold the downward gaze, and elicited no upward gaze (fig. 1A). Vertical saccades and pursuit returned normal on follow-up examination 2 weeks after onset. Bell's phenomenon was absent throughout his clinical course. MRI 7 days after onset showed fresh lacunar infarction in the midbrain tegmentum extended around the dorsal rim of the red nucleus on the left.

\section{Discussion}

Our patient had a well-demarcated, small infarct of the rostral midbrain dorsal to the red nucleus on the left. The lower pole of the lesion did not extend to the oculomotor nuclear complex because his left pupil was spared. Medio-laterally, it was not restricted to the dorso-medial region of the upper half of the red nucleus, where the critical structures for vertical gaze such as the rostral interstitial nucleus of medial longitudinal fasciculus (riMLF) and the interstitial nucleus of Cajal (INC) lie, but extended laterally involving a part of the mesencephalic reticular formation (MRF). A few autopsy cases with combined up- and downgaze palsy due to a unilateral lesion have been reported [2], in which two studied involved structures microscopically $[1,2]$. The riMLF on one side was involved sparing the PC in both cases. The INC, nucleus of Darkschewitsch, and the nucleus of PC were involved in one with non-dissociated vertical gaze palsy [1], but were spared in the other dissociated gaze palsy case [2]. The combined involvement of bilateral upgaze inhibitory inputs and unilateral downgaze excitatory inputs from a unilateral riMLF lesion may be sufficient to generate downgaze palsy [2], or a lesion of one INC may, through its contralateral projections via the $\mathrm{PC}$, affect inputs to ocular motoneurons on both sides $[1,5]$. Based on the case of our patient, we propose that the involvement of MRF lateral to the INC (peri-INC MRF [6]) may contribute to the combined upand downgaze palsy. In the monkeys, unilateral inactivation of the peri-INC MRF neurons produced a striking reduction in the gain of both up and down eye movements similar to the effect of bilateral riMLF lesions [6].

\section{KARGER}

Fax +41613061234

E-Mail karger@karger.ch

www.karger.com (c) 2008 S. Karger AG, Basel 0014-3022/08/0595-0272\$24.50/0

Accessible online at: www.karger.com/ene
Dr. Masashi Nakajima

Department of Neurology

Tokyo Rosai Occupational Diseases and Injuries Hospital

4-13-21 Ohmori-minami, Ohta-ku, Tokyo 143-0013 (Japan)

Tel. +81 33742 7301, Fax +81 33744 9310, E-Mail masashi@tokyoh.rofuku.go.jp 
Fig. 1. A Positions of gaze 5 days after onset. From top to bottom: upward gaze on oculocephalic maneuver, upward gaze, forward gaze, downward gaze, and downward gaze with oculocephalic maneuver. B-D Fluid-attenuated inversion recovery, $3-\mathrm{mm}$-thick MR images $(\mathrm{TE}=117 \mathrm{~ms}$, $\mathrm{TR}=8,000 \mathrm{~ms}$ ) showing a hyperintense signal dorsal to the left red nucleus, and old lacunar infarction in the right thalamus (C). The midbrain lesion attached medially to the cerebral aqueduct (B). Longitudinally, it extended from the floor of the third ventricle to the upper border of the superior colliculus (C, D).

\section{References}

1 Ranalli PJ, Sharpe JA, Fletcher WA: Palsy of upward and downward saccadic, pursuit, and vestibular movements with a unilateral midbrain lesion: pathophysiologic correlations. Neurology 1988;38:114-122.

2 Bogousslavsky J, Miklossy J, Regli F, Janzer $\mathrm{R}$ : Vertical gaze palsy and selective unilateral infarction of the rostral interstitial nucleus of the medial longitudinal fasciculus (riMLF). J Neurol Neurosurg Psychiatry 1990;53:67-71.

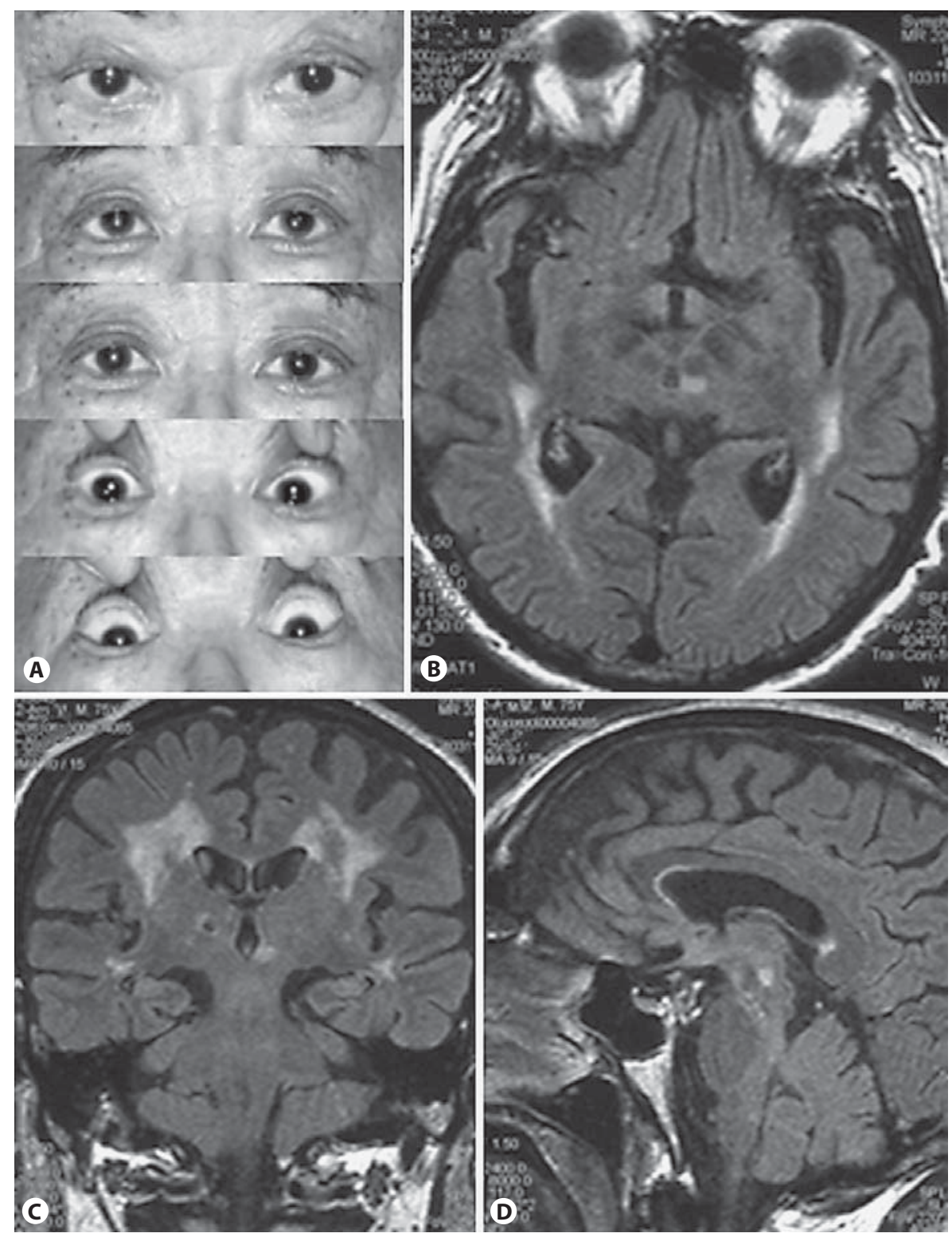

3 Alemdar M, Kamaci S, Budak F: Unilateral midbrain infarction causing upward and downward gaze palsy. J Neuroophthalmol 2006;26:173-176.

4 Hommel M, Bogousslavsky J: The spectrum of vertical gaze palsy following unilateral brainstem stroke. Neurology 1991;41:12291234.
5 Bhidayasiri R, Plant GT, Leigh RJ: A hypothetical scheme for the brainstem control of vertical gaze. Neurology 2000;54:19851993.

6 Waitzman DM, Silakov VL, DepalmaBowles S, Ayers AS: Effects of reversible inactivation of the primate mesencephalic reticular formation: II. hypometric vertical saccades. J Neurophysiol 2000;83:22852299. 